\title{
Insulin Glargine versus Insulin Detemir: Glycemic Control and Insulin Dose in Type 2 Diabetes Mellitus Patients Using a Medical Record Linkage System in the Netherlands
}

\author{
Ingo A Eland ${ }^{1 *}$, Edith M. Heintjes ${ }^{2}$, Leanne Houweling ${ }^{2}$, Ricardo deGrooth ${ }^{3}$, Thiemo F. Veneman ${ }^{4}$ and K. Paul Bouter $^{5}$
}

${ }^{1}$ Department of Internal Medicine, St. Antonius Hospital, Nieuwegein, The Netherlands

${ }^{2}$ PHARMO Institute, Utrecht, The Netherlands

${ }^{3}$ sanofi-aventis Netherlands B.V., Gouda, The Netherlands

${ }^{4}$ Department of Internal Medicine, ZGT Hengelo, Hengelo, The Netherlands

${ }^{5}$ Department of Internal Medicine, Jeroen Bosch Hospital, Den Bosch, The Netherland

\begin{abstract}
Background: In randomized controlled trials, patients with type 2 diabetes mellitus required higher doses of insulin detemir than insulin glargine to obtain the same glycemic control. However, this may differ in daily clinical practice.

Methods: We conducted a cohort study to compare glycemic control, daily basal insulin dose and persistence in The Netherlands. Data were obtained from the PHARMO record linkage system. Patients starting glargine or detemir in 2004 through 2007 were included if they had a follow-up and history of at least 1 year, including glycated hemoglobin $\left(\mathrm{HbA}_{1 \mathrm{c}}\right)$ measurements. Glycemic control and insulin dose were compared within 1 year after start of treatment. Average insulin dose was calculated based on the amount of insulin dispensed over time.

Results: A total of 708 patients on glargine and 298 on detemir were included. Patients starting glargine had less often used insulin in the previous year $(19$ versus $31 \%, P<0.001)$ and less often used oral antihyperglycemic drugs concomitantly $\left(61\right.$ versus $67 \%, P<0.05$ ) than those starting detemir. Despite a higher mean $\mathrm{HbA}_{1}$ at baseline in patients who started glargine $(8.6 \%$ versus $8.4 \%)$, the change from baseline in $\mathrm{HbA}_{1 \mathrm{c}}$ at follow-up was greater with glargine $(-0.9 \%)$ than with detemir $(-0.4 \%, P<0.001)$. The proportion of patients with $\mathrm{HbA}_{1 \mathrm{c}}<7 \%$ was similar between the two cohorts. Mean insulin dose at follow-up was significantly lower with glargine than with detemir (31.3 IU versus 36.6 IU, $P<0.01)$.
\end{abstract}

Conclusions: Patients with type 2 diabetes mellitus who were treated with insulin glargine achieved better glycemic control with lower insulin doses than did patients who were treated with insulin detemir.

Keywords: Insulin detemir; Insulin glargine; Type 2 diabetes; Glycemic control; Insulin dose; The Netherlands

Abbreviations: ADA: American Diabetes Association; CI: Confidence Interval; EASD: European Association for the Study of Diabetes; GP: General Practitioner; $\mathrm{HbA}_{1 c}$ : Glycated Hemoglobin; NPH: Neutral Protamine Hagedorn; OAD: Oral Antihyperglycemic Drug; SD: Standard Deviation; T2DM: Type 2 Diabetes Mellitus

\section{Introduction}

Type 2 diabetes mellitus (T2DM) is characterized by both insulin resistance and a progressive decline in insulin secretion. This means that for most patients with T2DM, intensification of blood glucoselowering therapy, including the use of insulin, becomes inevitable over time $[1,2]$. In addition, landmark clinical trials such as the United Kingdom Progressive Diabetes Study have shown that good glycemic control early in the disease process is mandatory to prevent longterm (macro) vascular complications [3]. National and international guidelines, such as the American Diabetes Association (ADA)/ European Association for the Study of Diabetes (EASD) consensus statement, therefore focus on timely intensification of blood glucoselowering treatment $[4,5]$. Basal insulin therapy is recommended as a first step of intensification by the ADA/EASD [4].

Several randomized, controlled trials have compared the efficacy and safety of the basal insulins, insulin glargine and insulin detemir, in patients with T2DM [6-10]. Detemir has been shown to require up to $75 \%$ higher doses than glargine to obtain comparable glycemic control $[8,9,11]$. Since results from randomized, controlled trials can differ considerably from results in a real-life setting $[12,13]$, we investigated glycemic control, persistence of insulin use, and insulin dose of glargine and detemir in daily practice in The Netherlands in a retrospective, observational cohort study.

\section{Materials and Methods}

This was a retrospective study of data obtained from the PHARMO medical record linkage system (PHARMO RLS) in The Netherlands. The PHARMO RLS is a population-based, patient-centric data tracking system that includes high quality, complete information of patient demographics, drug dispensings, hospital morbidity, clinical laboratory results, pathological findings, and general practitioner information of approximately 3.1 million patients in The Netherlands [14-17]. The population included is a sample of the general population, living in a geographically defined area where virtually all patient-filled

${ }^{*}$ Corresponding author: Dr. Ingo Eland, Department of Internal Medicine, St Antonius Hospital, Po Box. 2500, 3430 EM, Nieuwegein, The Netherlands, Tel: +3130 6099111; E-mail: i.eland@antoniusziekenhuis.nl

Received October 12, 2011; Accepted December 22, 2011; Published Decembe 26, 2011

Citation: Eland IA, Heintjes EM, Houweling L, deGrooth R, Veneman TF, et al. (2011) Insulin Glargine versus Insulin Detemir: Glycemic Control and Insulin Dose in Type 2 Diabetes Mellitus Patients Using a Medical Record Linkage System in the Netherlands. J Diabetes Metab 2:165. doi:10.4172/2155-6156.1000165

Copyright: (C) 2011 Eland IA, et al. This is an open-access article distributed unde the terms of the Creative Commons Attribution License, which permits unrestricted use, distribution, and reproduction in any medium, provided the original author and source are credited. 
Citation: Eland IA, Heintjes EM, Houweling L, deGrooth R, Veneman TF, et al. (2011) Insulin Glargine versus Insulin Detemir: Glycemic Control and Insulin Dose in Type 2 Diabetes Mellitus Patients Using a Medical Record Linkage System in the Netherlands. J Diabetes Metab 2:165. doi:10.4172/2155-6156.1000165

prescriptions from general practitioner (GP) or specialist are captured in the PHARMO database.

\section{Study objectives}

The primary objective of this analysis was to compare glycemic control, using change in $\mathrm{HbA}_{1 \mathrm{c}}$ levels and insulin dose, between glargine and detemir in patients with T2DM.

\section{Patient selection}

Patients with T2DM, defined as those patients who at any time during their available history or follow-up have used oral antihyperglycemic drugs (OADs), were identified. Patients, who in addition to their OADs, started insulin treatment with glargine (Lantus, ATC code A10AE04) or detemir (Levemir, ATC code A10AE05) between January 2004 and December 2007 were included. Patients with one or more episodes of monotherapy with glargine or detemir (i.e. no use of other insulin preparations) were eligible, provided that at least one of these episodes was preceded by a year of history in the database and they had not used the same type of insulin in the year preceding that episode. The start date of the first episode meeting these requirements was called the cohort entry date, and the type of insulin used during this episode was called the index treatment. Patients were excluded if they did not have a follow-up of 1 year in the database or did not have $\mathrm{HbA}_{1 \mathrm{c}}$ measurements from the clinical laboratory recorded in the database both at baseline (i.e. in the year prior to cohort entry date or up to 2 weeks after cohort entry date) and at follow-up (6 weeks to 1 year after cohort entry or 2 weeks after a change in insulin treatment).

\section{Glycemic control and insulin dose}

Baseline $\mathrm{HbA}_{1 \mathrm{c}}$ measurements in the 1 year prior to and up to 2 weeks after cohort entry date were eligible as baseline values. If multiple measurements were available, the measurement closest to cohort entry date was selected. The measurement closest to 1-year follow-up, but within the index treatment period ( 6 weeks after cohort entry date up to maximally 2 weeks after a treatment change) was defined as the followup $\mathrm{HbA}_{1 c}$ measurement. For baseline fasting glucose, the measurement closest to cohort entry date was selected. The measurement of fasting glucose closest to the 1 year of follow-up, but within the time up to a treatment change, was defined as the follow-up measurement. The availability of fasting glucose levels was not required for inclusion. Persistence was defined as the percentage of patients who continued the original treatment with glargine or detemir for the 1-year follow-up without any changes, including adding fast-acting insulin.

Insulin dose amounts were not directly obtained from the medical records; estimations of the dose were calculated based on the dispensed amount of insulin over time. An algorithm for the calculation of the insulin dose was made taking several considerations into account (e.g. patients usually keep a 'buffer supply' of insulin at home, titration of the insulin dose will likely take place in the first few months of therapy, and the dispensed amount of insulin will be larger than the amount injected). If insulin was dispensed two or more times in the first 6 months, the insulin starting dose was determined by dividing the amount of insulin dispensed the first two times by the number of days between the first and third times. No insulin starting dose was calculated when insulin was only dispensed once within the first 6 months or when a second dispensing within 6 months of cohort entry date was not followed by a third dispensing. The dose at follow-up was calculated similarly, using the last two measurements before the followup measurement, provided that they were followed by a third insulin dispensing within maximally 6 months of the second dispensing. This method has been used in other studies using real life data $[18,19]$. Although this dose estimation may be an overestimation of the actual administered dose because excess insulin may be disposed of some weeks after first use of a prefilled insulin pen, the error was assumed to be equal for both insulin types. Glycemic control and insulin dose were compared within 1 year after start of treatment but before any treatment change.

\section{Statistics}

All data were analyzed using SAS programs organized within SAS Enterprise Guide version 3.0 (SAS Institute Inc., Cary, NC, USA) and conducted under UNIX using SAS version 9.1. Univariate comparisons of categorical patient characteristics, glycemic parameters, and the proportion of patients with insulin treatment changes within 1 year of follow-up were compared between users of glargine and detemir using Chi-squared tests. Continuous data, such as $\mathrm{HbA}_{1 \mathrm{c}}$ levels and reductions, glucose levels, and time to treatment change were compared between users of glargine and detemir using $t$ tests. The association between insulin type and glycemic control was tested with univariate and multivariate linear regression methods with change in $\mathrm{HbA}_{1 c}$ level as the dependent variable. To adjust for possible confounders, univariate analyses were performed first to determine which patient characteristics (except for covariates with a frequency of $<5 \%$ in one of the treatment groups and concomitant OAD use) were associated with change in $\mathrm{HbA}_{1 \mathrm{c}}$ level. A multivariate model was built on the basis of the univariate analyses. Age, gender, and baseline $\mathrm{HbA}_{1 c}$ by definition were included in the multivariate model. Patient characteristics that changed the regression coefficient of insulin type by at least $5 \%$ were retained in the multivariate model. The order of introduction of each of the covariates was determined by the magnitude of their univariate association with $\mathrm{HbA}_{1 \mathrm{c}}$. The multivariate model was corrected for prior insulin use.

\section{Results}

A total of 1006 patients with T2DM (glargine, $n=708$; detemir, $n=$ 298) were included in the analysis (Figure 1). Patients starting glargine were slightly younger, had less often used insulin in the previous year, and had less often used OADs concomitantly than those starting

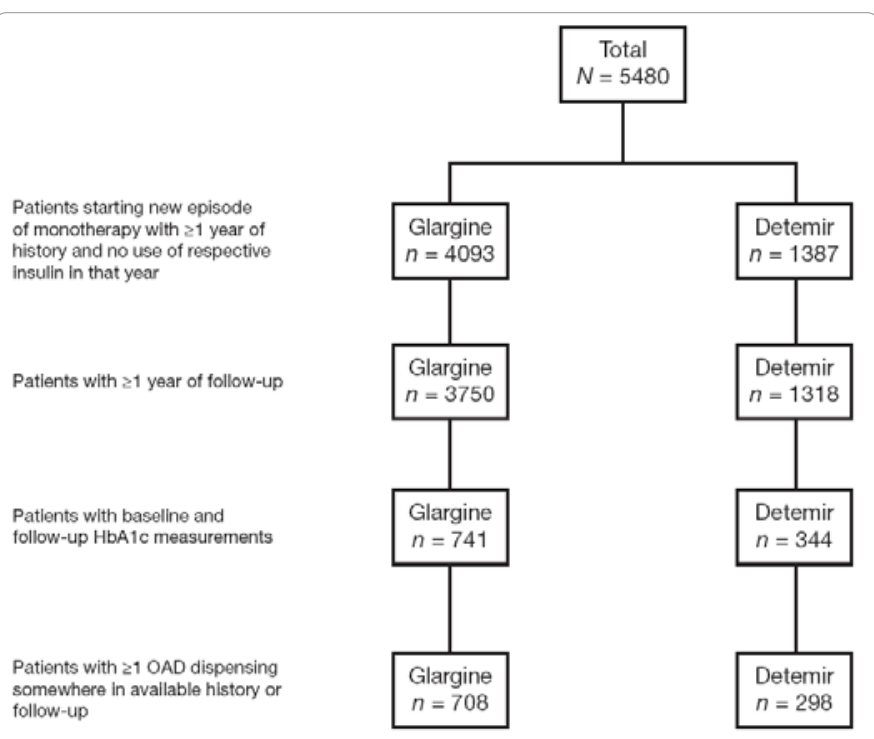

Figure 1: Patient selection (Detemir number $[n=344]$ is being fixed). 
Citation: Eland IA, Heintjes EM, Houweling L, deGrooth R, Veneman TF, et al. (2011) Insulin Glargine versus Insulin Detemir: Glycemic Control and Insulin Dose in Type 2 Diabetes Mellitus Patients Using a Medical Record Linkage System in the Netherlands. J Diabetes Metab 2:165. doi:10.4172/2155-6156.1000165

Page 3 of 5

detemir (Table 1). About two-thirds of all patients concomitantly used OADs with their index treatment. Cardiovascular comedication and comorbidity were similar between patients starting glargine and detemir. Approximately $20 \%$ of all patients had a hospitalization for cardiovascular disease in their total available history, most of whom had been hospitalized for ischemic heart disease. Over two-thirds of all patients used antihypertensive medications, and over one-third used platelet inhibitors in the year prior to cohort entry date.

\section{Insulin dose and glycemic parameters}

The mean starting dose of insulin was similar in the two cohorts, whereas the mean dose at follow-up was significantly lower in patients who started glargine than in those who started detemir (Table 2). Despite a higher mean $\mathrm{HbA}_{1 \mathrm{c}}$ at baseline in patients who started glargine, $\mathrm{HbA}_{1 \mathrm{c}}$ was lower at follow-up and the change from baseline in $\mathrm{HbA}_{1 \mathrm{c}}$ was greater in these patients than in those who started detemir (Table 2). The proportion of patients at goal $\left(\mathrm{HbA}_{1 c}<7 \%\right)$ was similar between the two cohorts. Mean baseline fasting plasma glucose levels were higher for patients who started glargine than for those who started detemir, but the levels were similar in the two cohorts at followup (Table 2). The change from baseline was significantly greater for patients who started glargine compared with those who started detemir.

\section{Persistence}

Of the patients who started glargine, $63 \%$ persisted with their treatment for 1 year compared with $49 \%$ of patients who started detemir $(P<0.001)$. Mean (standard deviation $[S D])$ time to treatment change was 208 (74) days for patients who started glargine and 199 (83) days for patients who started detemir.

\section{Multivariate analysis of $\mathrm{HbA}_{1 \mathrm{c}}$ reduction}

The association between the type of insulin used and glycemic control was tested by multivariate regressions (Table 3). Age, gender, year of start, prescriber, prior insulin use, and baseline $\mathrm{HbA}_{1 c}$ were retained in the multivariate model, whereas prior use of OADs, presence of any cardiovascular comorbidity, and the use of antihypertensive, platelet inhibitor, or nitrate comedications were not. After adjustment for these covariates, the mean $\mathrm{HbA}_{1 \mathrm{c}}$ reduction was still significantly greater for patients who started glargine compared with those who started detemir (-0.17; 95\% CI: $-0.31,-0.02)$.

\section{Discussion}

The results of this retrospective, observational cohort study of daily clinical practice in The Netherlands revealed that within 1 year of initiating insulin therapy a similar percentage of patients with T2DM achieved $\mathrm{HbA}_{1 \mathrm{c}}<7 \%$ with lower doses of insulin and slightly better $\mathrm{HbA}_{1 \mathrm{c}}$ when started on glargine than on detemir. Patients who started glargine also had a greater change in fasting blood glucose, and fewer of them changed treatment within 1 year compared with those who started detemir. These findings are limited, however, by the lack of recorded data on hypoglycemic episodes in the PHARMO medical record linkage system. The effects of either treatment on the incidence or severity of hypoglycemia could not be evaluated.

The lower dose requirement for glargine compared with detemir

\begin{tabular}{|c|c|c|c|}
\hline \multirow{2}{*}{ Characteristics } & $\begin{array}{c}\text { Glargine } \\
n=708\end{array}$ & $\begin{array}{l}\text { Detemir } \\
n=298\end{array}$ & Glargine versus detemir \\
\hline & $n(\%)$ & $n(\%)$ & Chi-square $P$ value \\
\hline Gender & & & 0.12 \\
\hline Male & $397(56)$ & $151(51)$ & \\
\hline Female & $311(44)$ & $147(49)$ & \\
\hline Age, mean (SD), years & $63(13)$ & $64(13)$ & $<0.05$ \\
\hline Prescriber & & & 0.75 \\
\hline General practitioner & $350(49)$ & $144(48)$ & \\
\hline Specialist & $358(51)$ & $154(52)$ & \\
\hline \multicolumn{4}{|l|}{ Prior anti-diabetics ${ }^{a}$} \\
\hline Insulin ${ }^{b}$ & $132(19)$ & $92(31)$ & $<0.0001$ \\
\hline OADs & $662(94)$ & $271(91)$ & 0.15 \\
\hline Concomitant OAD use & $430(61)$ & $201(67)$ & $<0.05$ \\
\hline \multicolumn{4}{|l|}{ Comorbidity $^{c}$} \\
\hline Any cardiovascular disease $^{d}$ & $123(17)$ & $64(21)$ & 0.13 \\
\hline Ischemic heart disease & $98(14)$ & $47(16)$ & 0.43 \\
\hline Cerebrovascular accident & $32(5)$ & $15(5)$ & 0.72 \\
\hline Peripheral vascular disease & $6(1)$ & $5(2)$ & 0.25 \\
\hline Congestive heart failure & $17(2)$ & $10(3)$ & 0.39 \\
\hline Chronic kidney disease & $0(0)$ & $1(<0.5)$ & 0.12 \\
\hline \multicolumn{4}{|l|}{ Comedication $^{e}$} \\
\hline Antihypertensives & $476(67)$ & $210(70)$ & 0.31 \\
\hline Platelet inhibitors & $264(37)$ & $110(37)$ & 0.91 \\
\hline Nitrates & 81 (11) & 37 (12) & 0.66 \\
\hline Digoxin & $31(4)$ & $15(5)$ & 0.65 \\
\hline
\end{tabular}

$\mathrm{SD}$, standard deviation; OADs, oral anti-diabetic drugs.

aln year prior to cohort entry date.

'Other type of insulin than index treatment.

'Based on hospitalizations in the total available history.

dIschemic heart disease or cerebrovascular accident or peripheral vascular disease.

eBased on drug dispensings in the year before cohort entry date.

Table 1: Patient baseline characteristics. 
Citation: Eland IA, Heintjes EM, Houweling L, deGrooth R, Veneman TF, et al. (2011) Insulin Glargine versus Insulin Detemir: Glycemic Control and Insulin Dose in Type 2 Diabetes Mellitus Patients Using a Medical Record Linkage System in the Netherlands. J Diabetes Metab 2:165. doi:10.4172/2155-6156.1000165

Page 4 of 5

\begin{tabular}{|c|c|c|c|c|c|c|}
\hline & \multicolumn{2}{|c|}{$\begin{array}{l}\text { Glargine } \\
(n=708)\end{array}$} & \multicolumn{2}{|c|}{$\begin{array}{l}\text { Detemir } \\
(n=298)\end{array}$} & \multicolumn{2}{|c|}{$\begin{array}{c}\text { Glargine versus detemir } \\
\qquad P \text { value }\end{array}$} \\
\hline & Baseline & Follow-up & Baseline & Follow-up & Baseline & Follow-up \\
\hline \multicolumn{7}{|l|}{ Insulin dose (IU) } \\
\hline$n(\%)$ & $629(89)$ & $629(89)$ & $254(85)$ & $254(85)$ & 0.11 & 0.11 \\
\hline Mean (SD) & $31.2(24.0)$ & $31.3(22.6)$ & $32.0(22.7)$ & $36.6(24.8)$ & 0.68 & $<0.01$ \\
\hline \multicolumn{7}{|l|}{$\mathrm{HbA}_{1 \mathrm{c}}(\%)$} \\
\hline$n(\%)$ & $708(100)$ & $708(100)$ & $298(100)$ & $298(100)$ & & \\
\hline Mean (SD) & $8.6(1.4)$ & $7.7(1.2)$ & $8.4(1.4)$ & $7.9(1.2)$ & $<0.05$ & $<0.05$ \\
\hline Change from baseline, mean (SD) & & $-0.9(1.4)$ & & $-0.4(1.4)$ & & $<0.001$ \\
\hline Patients with $\mathrm{HbA}_{1 \mathrm{c}}<7 \%, n(\%)$ & $70(! 0)$ & $196(28)$ & $35(12)$ & $70(23)$ & 0.38 & 0.17 \\
\hline \multicolumn{7}{|l|}{ Fasting plasma glucose (mmol/L) } \\
\hline$n(\%)$ & $512(72)$ & $458(65)$ & $222(74)$ & $171(57)$ & 0.48 & 0.48 \\
\hline Mean (SD) & $11.0(3.9)$ & $8.6(3.0)$ & $10.4(3.5)$ & $8.6(2.8)$ & $<0.05$ & $<0.05$ \\
\hline Change from baseline, mean (SD) & & $-2.6(4.3)$ & & $-1.8(3.8)$ & & $<0.05$ \\
\hline
\end{tabular}

Table 2: Baseline and follow-up insulin dose and glycemic parameters.

\begin{tabular}{|c|c|c|c|c|}
\hline & \multicolumn{3}{|c|}{$\begin{array}{l}\text { Multivariate (adjusted) } \\
\text { regression coefficient }\end{array}$} & \multirow[b]{2}{*}{$P$ value } \\
\hline & $n$ & Estimate & $95 \% \mathrm{Cl}$ & \\
\hline \multicolumn{5}{|l|}{ Index treatment } \\
\hline Detemir & 298 & 0 & Reference & \\
\hline Glargine & 708 & -0.17 & $(-0.31,-0.02)$ & $<0.05$ \\
\hline \multicolumn{5}{|l|}{ Covariates } \\
\hline Age, years & 1006 & -0.01 & $(-0.01,0.00)$ & $<0.001$ \\
\hline \multicolumn{5}{|l|}{ Gender } \\
\hline Male & 548 & 0 & Reference & - \\
\hline Female & 458 & 0.13 & $(0.00,0.26)$ & 0.06 \\
\hline \multicolumn{5}{|l|}{ Start year } \\
\hline 2004 & 255 & 0 & Reference & - \\
\hline 2005 & 263 & 0.06 & $(-0.12,0.24)$ & 0.54 \\
\hline 2006 & 210 & -0.14 & $(-0.34,0.05)$ & 0.15 \\
\hline 2007 & 278 & 0.27 & $(0.08,0.45)$ & $<0.01$ \\
\hline \multicolumn{5}{|l|}{ Prescriber } \\
\hline General practitioner & 494 & 0 & Reference & - \\
\hline Specialist & 512 & -0.16 & $(-0.29,-0.03)$ & $<0.05$ \\
\hline \multicolumn{5}{|c|}{ Prior anti-diabetics use ${ }^{a}$} \\
\hline Insulin & 225 & 0.69 & $(0.52,0.85)$ & $<0.001$ \\
\hline Baseline $\mathrm{HbA}_{1 \mathrm{c}}(\%)$ & 1006 & -0.60 & $(-0.65,-0.55)$ & $<0.001$ \\
\hline
\end{tabular}

aBased on drug dispensings in the year before cohort entry date.

Table 3: Multivariate regression of $\mathrm{HbA}_{1 \mathrm{c}}$ reductions in patients with type 2 diabetes mellitus treated with glargine or detemir.

is consistent with results from randomized clinical trials $[8,9,11]$. The total insulin dose and the difference in dose between glargine and detemir were much greater in the clinical trials than in this retrospective analysis, most likely because of the forced titration paradigms and the controlled setting used in the clinical trials. Also, the dosing frequency per day in these paradigms is higher for detemir than for glargine. Whether this is also the case in our study could not be determined from the data. These factors probably also contributed to the greater improvement in $\mathrm{HbA}_{1 \mathrm{c}}$ and to the lack of a difference in glycemic control between glargine and detemir in the clinical trials [6-10]. When taken together, glargine appears to be more efficacious than detemir, i.e. either equivalent glycemic control is achieved with a lower dose of glargine than detemir (as is the case when both are titrated appropriately) or a smaller difference in insulin dose between analogs results in significantly greater glycemic control with glargine (as was observed in this analysis). Age, gender, year of start, prescriber, prior insulin use, and baseline $\mathrm{HbA}_{1 c}$ were shown by multivariate regression to contribute to the greater reduction in $\mathrm{HbA}_{1 \mathrm{c}}$ with glargine than detemir. Even after adjustment for these factors, the mean $\mathrm{HbA}_{1 c}$ reduction was still significantly greater with glargine than detemir. These results suggest that treating to target is less rigorously applied in daily clinical practice than in clinical trials.

This observational analysis of daily practice in The Netherlands shows that more patients started on glargine than detemir, which reflects the difference in prescribing patterns between the two analogs across the country and may be the result, at least in part, of greater 
Citation: Eland IA, Heintjes EM, Houweling L, deGrooth R, Veneman TF, et al. (2011) Insulin Glargine versus Insulin Detemir: Glycemic Control and Insulin Dose in Type 2 Diabetes Mellitus Patients Using a Medical Record Linkage System in the Netherlands. J Diabetes Metab 2:165. doi:10.4172/2155-6156.1000165

Page 5 of 5

experience with glargine than detemir. In The Netherlands, general practitioner guidelines for treating patients with T2DM recommend starting insulin therapy with Neutral Protamine Hagedorn (NPH) insulin, and switching to basal insulin analogs is only recommended if NPH insulin causes nocturnal hypoglycemia [5]. Thus, patients starting glargine or detemir are more likely to have more severe disease and therefore a higher probability of being more difficult to treat. The fact that a larger proportion of detemir users had used insulin the year before starting detemir treatment and were using more OADs suggests that glycemic parameters in these patients may have been even more difficult to manage. Information on duration of diabetes mellitus was not available. We were therefore not able to check whether patients on detemir had longer duration of diabetes mellitus at inclusion in the study. As detemir has been associated with a less pronounced weight gain, this group also could have been selected because they were more obese and thus more difficult to treat. These factors may also explain why detemir users were less persistent than glargine users. In this study, most of the patient characteristics that relate to disease severity, i.e. age, prescribing physician, and prior cardiovascular disease, were similar between the two cohorts, and thus the risk of cardiovascular disease would most likely also be similar. Hypoglycemic events were not separately recorded. Patients on glargine may have experienced more hypoglycemic events, explaining the lower HbAlc. However, a recent meta-analysis showed similar frequencies of hypoglycemic events in glargine and detemir users [20]. Unfortunately, information was unavailable on the body mass index of these two groups. In analyses of a geographically defined subpopulation with body mass index measurements available from GP monitoring data, we observed no difference between detemir and glargine users, but the data are limited. Because of the observational nature of this study, confounding by these factors and other unrecorded patient or physician characteristics cannot be excluded.

\section{Conclusion}

Compared with insulin detemir, better glycemic control was achieved with significantly lower doses of insulin glargine in patients with T2DM in a real-life setting in The Netherlands.

\section{Acknowledgments}

This research was funded by sanofi-aventis. Editorial assistance was provided by Tom Claus, PhD, of PPSI (a PAREXEL company) and was funded by sanofiaventis

\section{References}

1. Cook MN, Girman CJ, Stein PP, Alexander CM, Holman RR (2005) Glycemic control continues to deteriorate after sulfonylureas are added to metformin among patients with type 2 diabetes. Diabetes Care 28: 995-1000.

2. Heine RJ, Diamant M, Mbanya JC, Nathan DM (2006) Management of hyperglycaemia in type 2 diabetes: the end of recurrent failure? BMJ 333 : 1200-1204.

3. Holman RR, Paul SK, Bethel MA, Matthews DR, Neil HA (2008) 10-year followup of intensive glucose control in type 2 diabetes. N Engl J Med 359: 15771589.

4. Nathan DM, Buse JB, Davidson MB, Ferrannini E, Holman RR, et al. (2009) Medical management of hyperglycemia in type 2 diabetes: a consensus algorithm for the initiation and adjustment of therapy: a consensus statement of the American Diabetes Association and the European Association for the Study of Diabetes. Diabetes Care 32: 193-203.

5. Rutten GEHM, De Grauw WJC, Nijpels G, Goudswaard AN, Uitewaal PJM, et al. (2010) NHG-standaard Diabetes mellitus type 2 [article in Dutch]. Huisarts Wet 49: 137-152.

6. Hollander P, Cooper J, Bregnhoj J, Pedersen CB (2008) A 52-week multinational, open-label, parallel-group, noninferiority, treat-to-target trial comparing insulin detemir with insulin glargine in a basal-bolus regimen with mealtime insulin aspart in patients with type 2 diabetes. Clin Ther 30: 19761987.

7. Raskin P, Gylvin T, Weng W, Chaykin L (2009) Comparison of insulin detemi and insulin glargine using a basal-bolus regimen in a randomized, controlled clinical study in patients with type 2 diabetes. Diabetes Metab Res Rev 25: 542-548.

8. Rosenstock J, Davies M, Home PD, Larsen J, Koenen C, et al. (2008) A randomised, 52-week, treat-to-target trial comparing insulin detemir with insulin glargine when administered as add-on to glucose-lowering drugs in insulinnaive people with type 2 diabetes. Diabetologia 51: 408-416.

9. Swinnen SG, Snoek FJ, Dain MP, Devries JH, Hoekstra JB, et al. (2009) Rationale, design, and baseline data of the insulin glargine (Lantus) versus insulin detemir (Levemir) Treat-To-Target (L2T3) study: a multinational, randomized noninferiority trial of basal insulin initiation in type 2 diabetes. Diabetes Technol Ther 11: 739-743.

10. Swinnen SG, Dain MP, Aronson R, Davies M, Gerstein HC, et al. (2010) A 24-week, randomized, treat-to-target trial comparing initiation of insulin glargine once-daily with insulin detemir twice-daily in patients with type 2 diabetes inadequately controlled on oral glucose-lowering drugs. Diabetes Care 33: 1176-1178.

11. Swinnen SG, Devries JH (2009) Higher dose requirements with insulin detemir in type 2 diabetes--three cases and a review of the literature. Diabetes Res Clin Pract 84: e24-e26.

12. Benson K, Hartz AJ (2000) A comparison of observational studies and randomized, controlled trials. Am J Ophthalmol 130: 688

13. Concato J, Shah N, Horwitz RI (2000) Randomized, controlled trials, observational studies, and the hierarchy of research designs. $\mathrm{N}$ Engl $\mathrm{J}$ Med 342: 1887-1892.

14. Heintjes EM, Thomsen TL, Penning-van Beest FJ, Christensen TE, Herings RM (2010) Glycemic control and long-acting insulin analog utilization in patients with type 2 diabetes. Adv Ther 27: 211-222.

15. Herings RM, Bakker A, Stricker BH, Nap G (1992) Pharmaco-morbidity linkage: a feasibility study comparing morbidity in two pharmacy based exposure cohorts. J Epidemiol Community Health 46: 136-140.

16. Herings RM (2007) The PHARMO System. CNS Spectrum 9: 14-17.

17. Herk-Sukel MP, van de Poll-Franse LV, Lemmens VE, Vreugdenhil G, Pruijt JF, et al. (2010) New opportunities for drug outcomes research in cancer patients: the linkage of the Eindhoven Cancer Registry and the PHARMO Record Linkage System. Eur J Cancer 46: 395-404.

18. Sharplin P, Gordon J, Peters JR, Tetlow AP, Longman AJ, et al. (2009) Switching from premixed insulin to glargine-based insulin regimen improves glycaemic control in patients with type 1 or type 2 diabetes: a retrospective primary-care-based analysis. Cardiovasc Diabetol 8: 9.

19. Sharplin P, Gordon J, Peters JR, Tetlow AP, Longman AJ, et al. (2009) Improved glycaemic control by switching from insulin NPH to insulin glargine: a retrospective observational study. Cardiovasc Diabetol 8: 3.

20. Swinnen SG, Simon AC, Holleman F, Hoekstra JB, Devries JH (2011) Insulin detemir versus insulin glargine for type 2 diabetes mellitus. Cochrane Database Syst Rev 7: CD006383. 